\title{
Tissue damage, mutagenic effect and alteration in antioxidant defense in Danio rerio (Cypriniformes: Cyprinidae) after chronic exposure to Metformin hydrochloride.
}

\section{Natani Ribeiro Demarco}

Universidade Estadual do Oeste do Paraná: Universidade Estadual do Oeste do Parana

\section{Bárbara Zanardini}

Universidade Estadual do Oeste do Paraná: Universidade Estadual do Oeste do Parana

Matheus Felipe Zazula

Universidade Federal do Paraná: Universidade Federal do Parana

Thaís Sobjak

Universidade Federal de Minas Gerais

\section{Luciana Gregório D’Arce}

Universidade Estadual do Oeste do Paraná: Universidade Estadual do Oeste do Parana

Ana Tereza Bittencourt Guimarães ( $\nabla$ anatbguimaraes@gmail.com )

Universidade Estadual do Oeste do Parana https://orcid.org/0000-0002-3633-6484

\section{Research Article}

Keywords: Zebrafish, Oxidative stress, Micronucleus

Posted Date: February 18th, 2022

DOI: https://doi.org/10.21203/rs.3.rs-1351553/v1

License: (c) (i) This work is licensed under a Creative Commons Attribution 4.0 International License.

Read Full License 


\section{Abstract}

Metformin hydrochloride (MET) is an oral medication very prescribed for patients with diabetes, with a large part of its metabolites being eliminated in the urine. Basic sanitation systems are not fully effective in removing all the contaminants, promoting contamination to rivers and supply reservoirs. The objective of this study was to test the potential acute and chronic effects of MET on the antioxidant system, mutagenicity effects and tissue damages in the bioindicator $D$. rerio. The animals were acclimatized and separated into six groups and exposed to different concentrations of $\operatorname{MET}(0.00,0.25,0.50,0.75,1.25$ g. $\mathrm{L}^{-1}$ ) over a 96 hour period to determine the LC50. In another experiment, five groups of ten animals were separated as follows: four groups for evaluation of the chronic effect of $0.45 \mathrm{~g} . \mathrm{L}^{-1}$ of metformin hydrochloride (15, 30, 45 and 60 days) and, a negative control group (NC). The antioxidant system and the tissue damages of the muscle samples and, the mutagenicity in the blood samples were evaluated. The presence of oxidative stress and mutagenicity, together with the activation of the antioxidant system, can be visualized up to 30 days of treatment, with intense tissue damages in 60 days and the emergence of apoptotic cells, which is evidence of the toxic potential of this drug to non-target aquatic populations.

\section{Introduction}

Metformin hydrochloride is a guanidine-derived drug prescribed for the treatment of diabetes mellitus and polycystic ovaries (WITTERS, 2001). When lifestyle change alone is not sufficient to control glucose levels, 500-2500 mg of metformin hydrochloride are indicated for daily intake (KOROLKOVAS, 2015). In the metabolism in the human body, part of metformin is discarded into the environment through excretion. Metformin is not removed by basic sanitation systems, it soon ends up reaching water resources (streams, rivers and reservoirs) and contaminating non-target populations. Found in $89 \%$ of samples and $97 \%$ of rivers tested in a study conducted in the United States (BRADLEY et al., 2016), its presence in aquatic ecosystems has had a negative impact on fishes, as it affects the male fitness and impacting the health of natural populations (MACLAREN; WISNIEWSKI; MACLAREN, 2018).

Seen as one of the most common mechanisms in a toxic condition, oxidative stress is a consequence by the antioxidant system imbalance and reactions that lead to decreased cell homeostatic state. This state is a consequence of the elevation of reactive oxygen species (ROS) and the increase of oxidized molecules (SAMET; WAGES, 2018). The formation of ROS can induce an increase in markers related to protein metabolism and degradation (SCHERZ-SHOUVAL; ELAZAR, 2007). These changes can also trigger lipoperoxidation reactions, and increase DNA damage (CZARNY et al., 2018), leading to genomic instability, facilitating mutations, and triggering carcinogenic processes (FAYH et al., 2018).

There is still little information about the chronic effects of metformin hydrochloride in non-target populations, like fishes. Thus, it is important to carry out studies within this scope, and the aim of the present study was to evaluate the potential effects of metformin hydrochloride drug on the antioxidant system, as well as mutagenic effects and tissue damages using Danio rerio bioindicator evaluations. 


\section{Methodology}

\subsection{Acclimatization and Experimental Procedures}

The sample consisted of 120 adult male specimens of Danio rerio fish obtained from fish farmers duly regulated by the Brazilian Institute of Environment and Renewable Natural Resources (IBAMA), distributed in a completely randomized design. From these, half were used to verify the LC50 (50\% lethal concentration) and the others were used in an experiment to evaluate the chronic effect of metformin hydrochloride. This project was approved by the Animal Research Ethics Committee (CEUA - $n^{\circ} 53-17$ ) of the Western Paraná State University (UNIOESTE).

All animals were acclimated in aeration tanks with constant temperature $\left(24 \pm 0.5^{\circ} \mathrm{C}\right)$ for at least seven days, respecting the density of $1 \mathrm{~g}$ of fish. $\mathrm{L}^{-1}$ of water. The animals were fed with commercial fish food with $45 \%$ crude protein, twice a day, receiving $5 \%$ of the total aquarium biomass. In the chronic effect evaluation experiment, total aquarium water was changed weekly in all containers, including controls, and new treatments were added to each aquarium, characterizing in pressure experiments (GOTELLI; ELLISON, 2011). In addition to the new treatment, negative control water was redistributed in all aquariums in order to conserve the environment where the animal was conditioned, thus reducing the stress of the procedure. All aquariums were supplied using water from the artesian well that supplies the University.

In order to measure water quality throughout the experiments, water evaluations were performed in a parallel experiment under the same conditions. The evaluations were performed twice a week, evaluating the $\mathrm{pH}$ and the dissolved oxygen contractions using a $\mathrm{pH}$ meter and an oximeter, respectively. Ammonia and nitrite concentrations were evaluated using specific kits (ALFAKIT ${ }^{\circledR}$ ) adapted for microplates and readings by spectrophotometer at $620 \mathrm{~nm}$ and $490 \mathrm{~nm}$ wavelengths, respectively.

\subsection{Evaluation of $50 \%$ lethal concentration (LC50)}

To evaluate the LC50, the fishes were placed in five $10 \mathrm{~L}$ aquariums ( $\mathrm{n}=10$ per aquarium). The following concentrations of metformin hydrochloride were administered to the aquariums for 96 hours: $\mathrm{A}-0.25$

g.L $\mathrm{L}^{-1} ; \mathrm{B}-0.5 \mathrm{~g} . \mathrm{L}^{-1} ; \mathrm{C}-0.75 \mathrm{~g} . \mathrm{L}^{-1} ; \mathrm{D}-1.25 \mathrm{~g} . \mathrm{L}^{-1}$ plus one aquariums used as control: $\mathrm{E}-$ Negative control (acclimatized animals only). Throughout the experiment, mortality rates per treatment were recorded daily. The calculation of LC50 was estimated nonlinearly by probit regression using the QuasiNewton estimation method. The prediction of LC50 was defined by multiple regression analysis, based on predicted probabilities (U.S. EPA, 2011).

\subsection{Evaluation of chronic effects of metformin hydrochloride}

After evaluation of the LC50, another experiment was done, in which the total and standard lengths of other animals were measured, and they were weighed both in the initial treatment period and before euthanasia. These animals were stored in four $10 \mathrm{~L}$ aquariums $(n=10$ per aquarium) after initial 
weighing. In the aquariums, the sublethal concentration of $0.45 \mathrm{~g} \cdot \mathrm{L}^{-1}$ metformin hydrochloride (obtained in the previous experiment) was administered and subdivided according to the time of drug exposure: T15: exposure for 15 days; - T30: exposure for 30 days; - T45: exposure for 45 days; - T60: exposure for 60 days. One more aquarium had animals just conditioned and considered as control, they were kept for 60 days: T0 - Negative control (animals only acclimatized).

At the experimental times described above, the animals were anesthetized in water containing $30 \mathrm{mg}$ of eugenol per liter, according to the methodology suggested by Honczaryk and Inoue (2009) and reweighed. Then, still anesthetized, blood was collected for subsequent micronucleus test (MN) through the caudal fin section. The tail muscle was also removed with the aid of a scalpel for the analysis of the antioxidant system. After material collection, the animals were euthanized by eugenol saturation, according to the same methodology mentioned above and discarded in a hospital waste bag for appropriate purpose.

\subsection{Laboratory Tests}

\subsubsection{Sample Preparation}

The muscle of each animal from both experiments described above was placed in a microtube containing $1 \mathrm{~mL}$ of TRIS $\mathrm{HCl}$ Buffer $\mathrm{pH} 7.4$ and frozen at $-20^{\circ} \mathrm{C}$ until the following procedures were performed.

The samples were thawed on crushed ice for at least two hours and then homogenized in TRIS HCl pH 7.4 buffer solution for 5 minutes. The material was centrifuged at $13,680 \mathrm{G}$ at $4^{\circ} \mathrm{C}$ for 10 minutes and the supernatant placed in a new microtube and frozen again at $-20^{\circ} \mathrm{C}$. Protein quantitation of the samples was determined by the Bradford method using bovine serum albumin as standard (BRADFORD, 1976). The samples were analyzed by microplate spectrophotometry using $595 \mathrm{~nm}$ wavelength. All samples were subsequently normalized to $1 \mathrm{mg}$ of protein. $\mathrm{mL}^{-1}$.

\subsubsection{Antioxidant System Analysis}

The dosage of dismutase superoxide enzyme followed the protocol proposed by Crouch et al. (1981), whose principle is to quantify tetrazolium blue (NBT). $100 \mu \mathrm{l}$ of $100 \%$ ethanol was added in $300 \mu \mathrm{l}$ of the normalized samples and centrifuged at $13,680 \mathrm{G}$ at $4^{\circ} \mathrm{C}$ for 10 minutes. In a 96 -well microplate, $30 \mu$ of the triplicate sample supernatant was pipetted, to the blank $30 \mu \mathrm{l}$ of $25 \%$ ethanol in $200 \mathrm{mM}$ Tris- $\mathrm{HCl}$ buffer and $100 \mu \mathrm{l}$ of the hydroxylamine solution were pipetted. Absorbance measurements were performed at $560 \mathrm{~nm}$ for 90 minutes at 1-minute intervals. SOD unit expression was given to enzyme activity capable of inhibiting by $50 \%$ the oxidation of protein NBT. $\mathrm{mg}^{-1}$.

The catalase enzyme dosing process was carried out according to the protocol proposed by Aebi, (1984), which has as its principle the dismutation of peroxide, whose molar extinction coefficient is $40 \mathrm{M}^{-1} . \mathrm{cm}^{-1}$. $3 \mu \mathrm{L}$ of the normalized samples were pipetted into microplates for reading in ultraviolet spectrophotometry, and were added $297 \mu \mathrm{l}$ of the reaction system $(2.5 \mathrm{ml} 1.0 \mathrm{M}$ Tris-HCl Buffer, $5.0 \mathrm{mM}$ EDTA, pH 8.0; $47.32 \mathrm{ml}$ of deionized water and $70 \mu \mathrm{H}_{2} \mathrm{O}_{2}$ ). Subsequently, the absorbance was measured 
at $240 \mathrm{~nm}$ for 2 minutes at 10-second intervals. Unit was expressed in mmol of degraded $\mathrm{H}_{2} \mathrm{O}_{2} \cdot \mathrm{min}^{-1} \cdot \mathrm{mg}$ of protein $^{-1}$.

The principle of Glutathione Transferase (GST) activity analysis is that the enzyme catalyzes the conjugation of reduced glutathione (GSH) with the synthetic substrate CDNB (HABIG; PABST; JAKOBY, 1974). $20 \mu \mathrm{L}$ of the normalized/blank samples were pipetted in triplicate, and $20 \mu$ l of potassium phosphate buffer and $180 \mu \mathrm{l}$ of the reaction system (0.94 mM CDNB/GSH) were added at room temperature $\left(25^{\circ} \mathrm{C}\right)$. Absorbance measurements were performed at a wavelength of $340 \mathrm{~nm}$ for 5 minutes at 30-second intervals. The unit was expressed in nmol of formed thioether.min ${ }^{-1}$. $\mathrm{mg}_{\text {of }}$ protein $^{-1}$.

For the indirect quantification of peroxides, the protocol followed was that of Buege and Aust (1978). For sample preparation, a medium containing $0.33 \mathrm{mg} / \mathrm{ml}$ rate of protein was added to a medium containing $6.7 \%$ trichloroacetic acid (TCA) with a final volume of $180 \mu \mathrm{L}$ and vortexed. The material was then placed in an ice bath for 5 minutes and centrifuged for 5 minutes at $13,680 \mathrm{G}$ at $4^{\circ} \mathrm{C} .40 \mu \mathrm{L}$ of the supernatant and standard Malonaldehyde (MDA) concentrations were pipetted in triplicate into a reaction medium containing $21.42 \mathrm{mM}$ of TBA, $17.86 \mathrm{mM}$ of $\mathrm{NaOH}, 0.73 \mathrm{M}$ of TCA, $0.032 \mathrm{mM}$ of $\mathrm{BHT}, 3 \%$ ethanol in PBS. The reaction was read at $22^{\circ} \mathrm{C}$, after 60 minutes of incubation at $60^{\circ} \mathrm{C}$, at an absorbance of $535 \mathrm{~nm}$. Lipid peroxidation was estimated from standard MDA concentrations and results were expressed as nmol of MDA.mg protein ${ }^{-1}$.

\subsubsection{Mutagenicity Evaluation}

For the micronucleus test we followed the protocol according to the one proposed by Hooftman and Raat (1982) with adaptations. The blood taken from each specimen was dripped onto a slide and smeared, one per animal. The slides were kept dry for 24 hours, then fixed in absolute methanol for 10 minutes and an additional 24 hours of drying at room temperature. They were then stained for 10 minutes with Giemsa solution diluted with $0.06 \mathrm{M}$ (pH 6.8) phosphate buffer in the ratio of $1 \mathrm{~mL}$ dye to $20 \mathrm{~mL}$ buffer, washed in distilled water and brought to dryness again. One thousand red blood cells per slide were analyzed under a light microscope at 1000x magnification for the MN count and to analyze of blebbed cells, notched cells, bud, necrosis, binucleated cells, apoptosis and lobed nucleus, always statistically compared to the negative (low mutagenic potential).

\subsubsection{Tissue damages}

The muscle homogenates were utilized for analysis of aspartate and alanine aminotransferase (AST and $\mathrm{ALT})$, Creatinine, and total creatine kinase (CK) and muscular fraction of creatine kinase (CK-MB) were measured using enzymatic commercials kits assays (Bioclinß). The absorbances were read on a microplate spectrophotometer at 343 nanometers and 510 for creatinine.

\subsection{Statistical analysis}

The assumptions of normality (Shapiro-Wilk test) and homoscedasticity (Levene Test) were tested for all variables. The groups were compared by the One-way ANOVA or by the Kruskal Wallis test and, in case of 
statistical significance $(p<0.05)$, the post-hoc test was performed using the Tukey-HSD test or the Dunn test, respectively.

After univariate analysis, we performed principal component analyzes of variables related to matrices, the antioxidant system, mutagenic effects and tissue damage. For each matrix, data quality was assessed using the Kaiser-Meyer-Olkin criterion (overall $k>0.5$ ). The first main component of each analysis was considered as the summary of linear relationships, and therefore, representing a latent variable from each set of observed variables. Latent variables were compared between experimental groups using single factor ANOVA, followed by the Tukey-HSD post-hoc test. All inferential analyzes were performed using the R program (R Development Core Team, 2019), assuming a significance level of 0.05 .

\section{Results}

\section{$3.150 \%$ lethal concentration (LC50)}

It was found that the groups exposed to $0.25 \mathrm{~g} \cdot \mathrm{L}^{-1}(0 \%), 0.5 \mathrm{~g} \cdot \mathrm{L}^{-1}(8 \%)$ and negative control (8\%) did not show statistically significant differences regarding mortality $(p>0.05)$, observing differences from the concentration of $0.75 \mathrm{~g} . \mathrm{L}^{-1}(13 \%)$ and $1.25 \mathrm{~g} \cdot \mathrm{L}^{-1}(70 \%)(p<0.05)$.

From the observed data, application of the estimation method and expressing the results in a second order polynomial model, it was possible to estimate that the lethal concentration of $50 \%$ of the individuals (LC50) was 1.15 g. $\mathrm{L}^{-1}$ in 96 hours. The same LC50 calculation was also performed for 48 and $72 \mathrm{~h}$, with values of 2.55 and $1.26 \mathrm{~g} . \mathrm{L}^{-1}$, respectively. These data were evaluated by regression analysis, defining a negative exponential model (Fig. 1B). From the present model it was possible to infer that the LC50 value for seven days of exposure is $0.51 \mathrm{~g} . \mathrm{L}^{-1}$ of metformin hydrochloride. The calculation of this value was necessary since it would have to be reset weekly in the chronic exposure experiment, and a non-lethal concentration of $0.45 \mathrm{~g} . \mathrm{L}^{-1}$ of metformin hydrochloride was defined.

\subsection{Chronic exposure to metformin hydrochloride 3.2.1 Water quality and biometry of animals}

Regarding water quality, it was possible to observe that throughout the experiment there were no significant statistical differences in $\mathrm{pH}$ (General mean $=7.89 \pm 0.06 ; \mathrm{F}=0.989 ; \mathrm{p}=0.435$ ) and dissolved oxygen $(\mathrm{OD})$ (General mean $=7.92 \pm 0.42 ; \mathrm{H}=0.534 ; \mathrm{p}=0.749$ ) between treatments, remaining at values considered adequate for the conditioning of $D$. rerio. However, a statistically significant difference was found in the evaluation of ammonia, indicating a significant increase in values at $15,30,45$ and 60 days of exposure to metformin hydrochloride when compared to the negative control $(H=12.43 ; p<0.0001$; Table 1). On the other hand, for nitrite, no significant results can be observed $(H=0.31 ; p=0.863$; Table 1), indicating the similarity of the treatments with the negative control. 
Table 1

Medians, interquartile and interpercentric ranges of water quality variables (mg. $\mathrm{L}^{-1}$ ) in $D$. rerio exposed to $0.45 \mathrm{~g} . \mathrm{L}^{-}$

1 of Metformin Hydrochloride and Negative Control (NC) for 60 days (T60).

\begin{tabular}{|lll|}
\hline \multicolumn{3}{|c|}{ Md $\left(1^{\circ} \mathrm{Q}-3^{\circ} \mathrm{Q}\right)$} \\
\hline Treatments & Ammonia $\left(\mathrm{mg.L^{-1 }}\right)$ & Nitrite $\left(\mathrm{mg.L}^{-1}\right)$ \\
\hline T15 & $0.13(0.11-0.14)$ & $0.16(0.09-0.21)$ \\
\hline T30 & $0.10(0.08-0.11)$ & $0.08(0.06-0.13)$ \\
\hline T45 & $0.09(0.08-0.11)$ & $0.21(0.14-0.44)$ \\
\hline T60 & $0.09(0.08-0.14)$ & $0.11(0.07-0.20)$ \\
\hline NC & $0.01(0.01-0.04) *$ & $0.07(0.06-0.14)$ \\
\hline p-valor & $<0.0001$ & 0.863 \\
\hline
\end{tabular}

When observing the total length and standard length) of the animals, it was observed that there was no statistical difference between treatments $(p=0.202 ; p=0.182$, respectively. Regarding the weight variable, when comparing the initial and final weight of all animals, a significant weight loss can be observed (Difference mean $=-0.07 \pm 0.04 \mathrm{~g} ; \mathrm{V}=909.5 ; \mathrm{w}=0.008$ ).

\subsubsection{Antioxidant system}

Significant increase in SOD activity values $(F=8.752 ; p<0.0001)$ was observed among animals exposed to metformin hydrochloride in period of 30 days and the T0 group showed differences in relation to periods of T15 and T30 (Fig. 1A). No statistically significant difference was observed regarding CAT activity when comparing groups $(F=1.8 ; p=0.147$; Fig. $1 \mathrm{~B})$. Regarding $G S T$, a significant reduction activity was found at 15 and 30 days of drug exposure when compared to the negative control and others groups, being the T0 statistically same to the $T 60(F=39.74 ; p<0.0001 ;$ Fig. $1 \mathrm{C})$. In this analysis it was observed that the LPO reaction remained high in the first three treatment periods ( 15,30 and 45 days), but the same does not showed significant differences when compared to the others treatments $(F=8.11 ; p=$ 0.087; Fig. 1D).

\subsubsection{Mutagenic action}

There was a significant increase in the frequency of $\mathrm{MN}(\mathrm{H}=16.228 ; \mathrm{p}=0.002$; Table 2; Fig. 1E) and in the number of necrosis cells $(H=20.468 ; p=0.000$; Table 2; Fig. $1 F)$ over 15 days (T15) compared to other treatments, these being statistically different from T0. Binucleated cells $(H=4.397 ; p=0.355$; Table 2; Fig. $1 \mathrm{G})$ and cells with bud $(\mathrm{H}=5.727 ; \mathrm{p}=0.220$; Table 2; Fig. $1 \mathrm{H})$ showed no statistically significant differences. At 60 days (T60), an increase in the frequency of cellular apoptosis could be seen compared to the other groups, a statistic difference also could can seen when compared the periods of 15 (T15) and 30 days (T30), in which these showed lower levels of apoptosis than others treatments $(H=33.913 ; p<$ 
0.0001; Table 2; Fig. 1I). Already Blebbed $(H=10.3865 ; p=0.034$; Table 2$)$ and Lobed Nucleus $(H=$ 10.7937; $p=0.029$; Table 2), also was observed differences in the cellular frequencies, been that to Blebbed, T15 and T45 was different statistically (Table 2).

Table 2

- Medians and interquartile ranges of the variables analyzed in $1000 \mathrm{D}$. rerio erythrocytes exposed to 0.45 g.L ${ }^{-1}$ of Metformin Hydrochloride at different times: Negative Control (NC); 15 days (T15); 30 days (T30); 45 days (T45); 60 days (T60).

\begin{tabular}{|lllllll|}
\hline Treatments & NC & T15 & T30 & T45 & T60 & p-valor \\
\hline MN & 0 & 2 & 0 & 1 & 0 & 0.002 \\
\hline Necrosis & $(0-0)$ & $(1-2)^{\star}$ & $(0-1)$ & $(0-1)$ & $(0-0)$ & \\
\hline Binucleated & 0 & 7 & 0 & 3 & 0 & 0.000 \\
& $(0-0)$ & $(6-8)^{\star}$ & $(0-2)$ & $(1-7)$ & $(0-0)$ & \\
\hline Bud & $(0-0)$ & $(0-0)$ & $(0-0)$ & $(0-0.25)$ & $(0-0)$ & 0.354 \\
& 0 & 0 & 0 & 0 & 0 & 0.220 \\
\hline Apoptosis & $(0-0)$ & $(0-0.25)$ & $(0-1)$ & $(0-0.25)$ & $(0-0)$ & \\
& 157 & 13 & 8 & 147 & 222 & $>0.0001$ \\
\hline Blebbed & $(135-169)$ & $(1-21)^{\star}$ & $(1-10)^{\star}$ & $(75-168)$ & $(149-290)^{\star}$ & \\
& 0 & 0 & 0 & 0 & 1 & 0.034 \\
\hline Lobed Nucleus & 0 & $(0-1) *$ & $(0-0)$ & $(0.0-1)^{\star}$ & $(0.7-1.2)$ & \\
& $(0-0)$ & $(0-0)$ & $(0-1)$ & $(0-0)$ & $(0-0)$ & 0.029 \\
\hline
\end{tabular}

\subsubsection{Tissue damages}

When evaluating the variables that reflect tissue damage, we found that ALT $(k=34.901 ; p<0.0001$; Fig. 1J), AST ( $k=33.062 ; p<0.0001$; Fig. 1K), CK $(k=28.656 ; p<0.0001$; Fig. $1 \mathrm{~L})$ and CK-MB $(k=10.738$; $p=0.030$; Fig. $1 \mathrm{M}$ ) showed significant differences among groups. It was possible to verify that after 30 days of exposure to metformin hydrochloride there was a significant increase in the values of ALT and AST, and after 45 days there was an increase in CK and CK-MB.

\subsection{Integrative analysis}

Since organisms present their biological systems integrated, analyzes and interpretations must be carried out in an integrated manner. Therefore, we carried out evaluations in three systems: Antioxidant System, Mutagenic Effects and Tissue Damage. This evaluation was carried out with the Principal Component 
Analysis, evaluating only the first dimension of the analyses, since it is the component that accumulates the greatest variation in linear relationships. When performing the analysis for the variables related to the Antioxidant System, relationships between SOD, LPO and GST can be observed in the first dimension, the latter being inversely related to the others (Dimension 1 - Antioxidant System; Eigenvalue $=1.52$; Variance $=38.04 \%$; Fig. $2 \mathrm{~A}$ ). In this interpretation, we can verify the activation of the antioxidant system, increased oxidative stress and reduced detoxification capacity, especially in 30 days of exposure to Metformin Hydrochloride ( $F=9.05 ; p<0.0001 ;$ Fig. 2B).

As for the integrated assessment of variables related to DNA damage, we can see that the first dimension refers to the linear relationships of binucleate cells, bud formation, blebbed and apoptosis, the latter being inversely related to the others (Dimension 1 - Mutagenicity; Eigenvalue $=1.92$; Variance $=27.44 \%$; Fig. $2 \mathrm{C}$ ). We verified that in 15, 30 and 45 days there is an increase in binucleate cells, sprouts and blebbed, while in 60 days there is more occurrence of apoptosis $(F=6.309 ; p=0.0005 ; \mathrm{Fig} .2 \mathrm{D})$. Finally, regarding tissue damage, we found that the first dimension presents strong linear relationships between CK, ALT and AST, all of which are directly related (Dimension $1-$ Tissue Damage; Eigenvalue $=2.66$; Variance $=66.57 \%$; Fig. 2E). It was possible to verify the gradual increase in tissue damage, with greater intensity of damage being observed after 60 days of exposure to metformin hydrochloride $(F=35.791 ; p<0.0001$; Fig. $2 F)$.

\section{Discussion}

Metformin hydrochloride (MET) at a sublethal dose of $0.45 \mathrm{~g} \cdot \mathrm{L}^{-1}$ was able to promote persistent damage in erythrocytes and muscle of Danio rerio chronically exposed (60 days). The induction of a defense response by the antioxidant system and the installation of DNA damage up to 30 days was evidenced. These results reflect the change in protein metabolism, with a significant increase in ammonia excretion throughout the experimental period.

Environmental pollution induces cell detoxification in exposed organisms, which causes ROS production and increased activity of antioxidant enzymes as a defense mechanism. The present study demonstrated that MET induced the antioxidant system of Danio rerio. Antioxidant activity levels changed in a timedependent manner, as there was an increase in 15 days, followed by an activation peak in 30 days and gradual inhibition at 45 and 60 days. The induction of an antioxidant response has also been evaluated in Danio rerio embryos exposed to environmentally relevant concentrations of metformin with increased markers of oxidative damage (ELIZALDE-VELÁZQUEZ et al., 2021). The authors show that this response may have been caused by an inhibition of the mitochondrial complex I of the electron transport chain and a consequent increase in superoxide production and triggering of apoptosis mechanisms.

Considering that SOD is the first enzyme of antioxidant system (JIAO et al., 2020), we observed the increase in its activity until 30 days of exposure to MET, considering an active cellular defense. However this primary system began to be insufficient to defend against the constant production of ROS. The same response was identified in the CAT enzyme to try to eliminate the accumulation of hydrogen peroxide from metabolism reactions. Thus, the change in the redox balance of cells activated the antioxidant 
defense of GST, as can be seen at 45 days of exposure to MET, with its activation being significantly high, thus representing a second line of cellular defense against oxidative pressure to convert this xenobiotic and fulfill detoxification (Li et al., 2018).

Despite the activation of the antioxidant system up to 30 days of exposure to the xenobiotic, the large period of the animals' exposure to MET promoted an increase in cell damage and apoptosis markers. An important feature found in animals chronically exposed to MET was the increased activity of aminotransferases (ALT and AST), both being markers of changes in the energy metabolism of these animals (KHAN et al., 2020; MEADOR; YEH; GALLAGHER, 2018). Likewise, the late increase (after 45 days of exposure) in the activity of creatinine kinase enzymes may be associated with the failure of the repair system and apoptosis induction, how observed by others researchers (SONG et al., 2018; UCAR et al., 2019; WANG et al., 2019).

At the end of exposure for 60 days, the potential toxicity of MET was also able to significantly induce the state of cellular apoptosis. Li et al. (2020) point out that the induction of the apoptotic process may be a result from the increase in the generation of ROS, activating a mitochondrial signaling pathway mediated by ROS. The same authors mention that this effect may be related to increased tissue damage in Zebrafish fish.

In addition to the study of antioxidant system, it was also possible to observe an increase in the levels of Lipoperoxidation in the first days of treatment, even though it did not show statistical significance ( $p$ > 0,05). According to Voulgaridou et al. (2011), LPO products can induce mutations in DNA strands, which over time can develop a carcinogenic process. With the peroxidation of fatty acids, the formation of lipid peroxyl occurs, which can be later converted into secondary aldehyde species, which can result in cell damage (MUSTAFA et al., 2017). This type of cell damage was observed in the present study, with a simultaneous increase in the number of $\mathrm{MN}$ and Blebbed cells, which are indicators of mutagenicity within a 15-day period. Along with the induction of mutagenic processes, it is possible to visualize the increase of cells in a state of necrosis over the exposure to MET, which demonstrates the possible cytotoxic potential of the drug, concomitantly with the increase in ROS. According to Malhi; Gores and Lemasters (2006), a common event that can trigger both the necrotic and the apoptotic processes is permeabilization and mitochondrial dysfunction.

The induction of protein metabolism evidenced by the increase in muscle phosphotransferases and transaminases, together with the subsequent loss of antioxidant defense and the increase in cellular apoptosis (after 45 days), can promote the loss of the animals' homeostatic regulation capacity. The synthesis of this discussion may be observed in the diagram exposed below (Fig. 3).

Therefore, considering that xenobiotics, such as Metformin Hydrochloride (widely used by the human population in the treatment of Diabetes and Polycystic Ovary Syndrome), are not fully purified in the sewage treatment systems of cities and, therefore, are constantly dumped in rivers and streams, it can be said that aquatic animals are in constant exposure to such chemicals. The present study demonstrated that chronic exposure to these xenobiotics promotes functional changes on the fish Danio rerio. Such 
functional changes can reduce the fish ability to search for food, reproduction and survival, reflecting negatively on the populations. Therefore, there is a need for studies that develop systems for the removal of xenobiotics in the treatment of sewage in cities, since there is currently evidence reported in the scientific literature that demonstrate the deleterious effects of these chemicals, constantly dumped in streams, on the aquatic fauna.

\section{Conclusion}

The present study demonstrated the toxic potential of MET in chronically exposed animals (60 days). There was an induction of a response from the antioxidant system, followed by an inhibition of this system concomitant with the appearance of cellular and mutagenic damage. Toxic effects can reduce the ability of exposed animals to survive.

\section{Declarations}

Ethics Approval: The experiment was authorized by the Ethics Committee in Animal Experimentation of the Universidade Estadual do Oeste do Paraná (CEUA- n.53-17).

Consent to Participate: Not applicable.

Consent to Publish: Not applicable.

Availability of data and materials: Not applicable.

Competing Interests: The authors declare that they have no competing interests.

Funding: This work has been financially supported by the Conselho Nacional de Desenvolvimento Científico e Tecnológico- CNPq (422443/2016-6).

Author Contributions: NRD: Data curation, Visualization, Investigation, Writing-original draft. BZ: Visualization, Writing-original draft. MFZ: Visualization, Writing-original draft. TS: Writing-review \& editing. LGDA: Writing-review \& editing. ATBG: Conceptualization, Data curation, Visualization, Writing-original draft, Methodology, Resource, Funding acquisition, Formal analysis, Project administration, Supervision. All authors read and approved the final manuscript.

Acknowlegement. Authors are grateful for the financial support of CNPq and the logistical support of UNIOESTE.

\section{References}

AEBI, H. Catalase in Vitro. Methods in Enzymology, [S. I.], v. 105, p. 121-126, 1984. Disponível em: https://doi.org/10.1016/S0076-6879(84)05016-3 
BRADFORD, M. M. A Rapid and Sensitive Method for the Quantitation of Microgram Quantities of Protein Utilizing the Principle of Protein-Dye Binding. Analytical biochemistry, [S. I.], v. 72, n. 1-2, p. 248-254, 1976. Disponível em: https://doi.org/https://doi.org/10.1016/0003-2697(76)90527-3

BRADLEY, Paul M. et al. Metformin and other pharmaceuticals widespread in wadeable streams of the southeastern United States. Environmental Science and Technology Letters, [S. I.], v. 3, n. 6, p. 243-249, 2016. Disponível em: https://doi.org/10.1021/acs.estlett.6b00170

BUEGE, John A.; AUST, Steven D. Microsomal lipid peroxidation. Methods in Enzymology, [S. I.], v. 52, p. 302-310, 1978. Disponível em: https://doi.org/10.1016/S0076-6879(78)52032-6

CROUCH, R. K. et al. The inhibition of islet superoxide dismutase by diabetogenic drugs. Diabetes, [S. I.], v. 30, n. 3, p. 235-241, 1981. Disponível em: https://doi.org/10.2337/diab.30.3.235

CZARNY, Piotr et al. The interplay between inflammation, oxidative stress, DNA damage, DNA repair and mitochondrial dysfunction in depression. Progress in Neuro-Psychopharmacology and Biological Psychiatry, [S. I.], v. 80, n. June, p. 309-321, 2018. Disponível em: https://doi.org/10.1016/j.pnpbp.2017.06.036

ELIZALDE-VELÁZQUEZ, Gustavo Axel et al. Antidiabetic drug metformin disrupts the embryogenesis in zebrafish through an oxidative stress mechanism. Chemosphere, [S. I.], v. 285, n. July, p. 1-10, 2021. Disponível em: https://doi.org/10.1016/j.chemosphere.2021.131213

FAYH, Ana Paula Trussardi et al. Induction chemotherapy reduces extracellular heat shock protein 72 levels, inflammation, lipoperoxidation and changes insulin sensitivity in children and adolescents newly diagnosed with acute lymphoblastic leukemia. Oncotarget, [S. I.], v. 9, n. 47, p. 28784-28795, 2018. Disponível em: https://doi.org/10.18632/oncotarget.25609

GOTELLI, Nicholas J.; ELLISON, Aaron M. Princípios de estatística em ecologia. [S. I.: s. n.]. E-book.

HABIG, W. H.; PABST, M. J.; JAKOBY, W. B. Glutathione S transferases. The first enzymatic step in mercapturic acid formation. Journal of Biological Chemistry, [S. I.], v. 249, n. 22, p. 7130-7139, 1974. Disponível em: https://doi.org/10.1016/S0021-9258(19)42083-8

HONCZARYK, Alexandre; INOUE, Luís Antonio Kioshi Aoki. Anesthesia in pirarucu by eugenol sprays in the gills. Ciencia Rural, [S. I.], v. 39, n. 2, p. 577-579, 2009. Disponível em: https://doi.org/10.1590/s010384782008005000084

HOOFTMAN, Ria N.; DE RAAT, W. K. Induction of nuclear anomalies (micronuclei) in the peripheral blood erythrocytes of the eastern mudminnow Umbra pygmaea by ethyl methanesulphonate. Mutation Research Letters, [S. I.], v. 104, n. 1-3, p. 147-152, 1982. Disponível em: https://doi.org/10.1016/01657992(82)90136-1 
JIAO, Yaqi et al. Monobutyl phthalate (MBP) can dysregulate the antioxidant system and induce apoptosis of zebrafish liver. Environmental Pollution, [S. I.], v. 257, n. 2020, p. 113517, 2020. Disponível em: https://doi.org/10.1016/j.envpol.2019.113517

KHAN, Mohd Shahnawaz et al. Heavy metal pollution and risk assessment by the battery of toxicity tests. Scientific Reports, [S. I.], v. 10, n. 1, p. 16593, 2020. Disponível em: https://doi.org/10.1038/s41598020-73468-4

KOROLKOVAS, Andrejus. Dicionário Terapêutico Guanabara- DTG. [S. I.: s. n.]. E-book.

$\mathrm{LI}$, Xiuwen et al. The assessment of the eco-toxicological effect of gabapentin on early development of zebrafish and its antioxidant system. RSC Advances, [S. I.], v. 8, n. 40, p. 22777-22784, 2018. Disponível em: https://doi.org/10.1039/c8ra04250k

$\mathrm{LI}$, Zekang et al. Polystyrene microplastics cause cardiac fibrosis by activating Wnt/ $\beta$-catenin signaling pathway and promoting cardiomyocyte apoptosis in rats. Environmental Pollution, [S. I.], v. 265, p. 115025, 2020. Disponível em: https://doi.org/10.1016/j.envpol.2020.115025

MACLAREN, Ronald David; WISNIEWSKI, Kathryn; MACLAREN, Christina. Environmental concentrations of metformin exposure affect aggressive behavior in the siamese fighting fish, betta splendens. PLoS ONE, [S. I.], v. 13, n. 5, p. 6-8, 2018. Disponível em: https://doi.org/10.1371/journal.pone.0197259

MALHI, Harmeet; GORES, Gregory J.; LEMASTERS, John J. Apoptosis and necrosis in the liver: A tale of two deaths? Hepatology, [S. I.], v. 43, n. 2 SUPPL. 1, p. 31-44, 2006. Disponível em:

https://doi.org/10.1002/hep.21062

MEADOR, James P; YEH, Andrew; GALLAGHER, Evan P. Adverse metabolic effects in fish exposed to contaminants of emerging concern in the field and laboratory. Environmental Pollution, [S. I.], v. 236, 2018. Disponível em: https://doi.org/10.1016/j.envpol.2018.02.007

MUSTAFA, Ayman G. et al. Phenelzine reduces the oxidative damage induced by peroxynitrite in plasma lipids and proteins. Archives of Physiology and Biochemistry, [S. I.], v. 124, n. 5, p. 418-423, 2017. Disponível em: https://doi.org/10.1080/13813455.2017.1415939

R DEVELOPMENT CORE TEAM. R: A Language and Environment for Statistical Computing. [S. I.], 2018. Disponível em: https://www.r-project.org/

SAMET, James M.; WAGES, Phillip A. Oxidative stress from environmental exposures. Current Opinion in Toxicology, [S. I.], v. 7, p. 60-66, 2018. Disponível em: https://doi.org/10.1016/j.cotox.2017.10.008

SCHERZ-SHOUVAL, Ruth; ELAZAR, Zvulun. ROS, mitochondria and the regulation of autophagy. Trends in Cell Biology, [S. I.], v. 17, n. 9, p. 422-427, 2007. Disponível em: https://doi.org/10.1016/j.tcb.2007.07.009 
SONG, Yu Feng et al. Upstream regulators of apoptosis mediates methionine-induced changes of lipid metabolism. Cellular Signalling, [S. I.], v. 51, 2018. Disponível em:

https://doi.org/10.1016/j.cellsig.2018.08.005

U.S. EPA. Highlights of the Exposure Factors Handbook. EPA/600/R-10/030. Washington, DC: [s. n.], 2011. E-book.

UCAR, Arzu et al. The effect of $\mathrm{N}$-acetylcysteine supplementation on the oxidative stress levels, apoptosis, DNA damage, and hematopoietic effect in pesticide-exposed fish blood. Journal of Biochemical and Molecular Toxicology, [S. I.], v. 33, n. 6, 2019. Disponível em: https://doi.org/10.1002/jbt.22311

VOULGARIDOU, Georgia Persephoni et al. DNA damage induced by endogenous aldehydes: Current state of knowledge. Mutation Research - Fundamental and Molecular Mechanisms of Mutagenesis, [S. I.], v. 711, n. 1-2, p. 13-27, 2011. Disponível em: https://doi.org/10.1016/j.mrfmmm.2011.03.006

WANG, Nan et al. Effect of Bacillus cereus against cadmium induced hematological disturbances and immunosuppression in Carassius auratus gibelio. Fish and Shellfish Immunology, [S. I.], v. 89, 2019. Disponível em: https://doi.org/10.1016/j.fsi.2019.03.047

WITTERS, L. A. The blooming of the French lilac. Journal of Clinical Investigation, [S. I.], v. 108, n. 8, p. 1105-1107, 2001. Disponível em: https://doi.org/10.1172/JCl14178

\section{Figures}



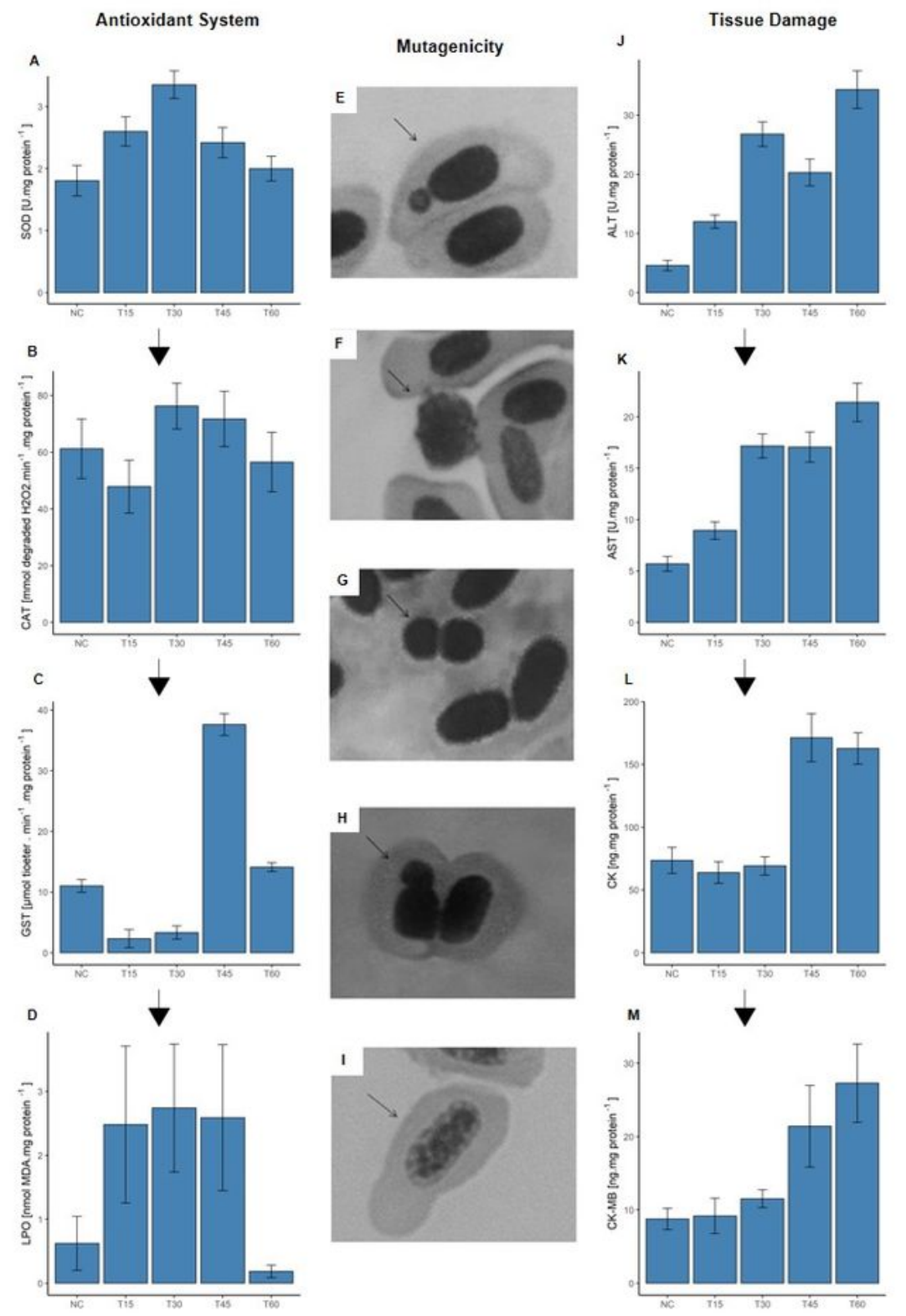

\section{Figure 1}

Means and standard error of the antioxidant system variables and tissue damages, and types of mutagenicity cells analyzed in $D$. rerio muscle, exposed to $0.45 \mathrm{~g} . \mathrm{L}^{-1}$ of Metformin Hydrochloride at different treatments: 15 days (T15); 30 days (T30); 45 days (T45); 60 days (T60); and the Negative Control (NC). A) SOD; B) CAT; C) GST; D) LPO; E) MN; F) Necrosis; G) Binucleated; H) Bud; I) Apoptosis; J) ALT; K) AST; L) CK and M) CK-MB. 

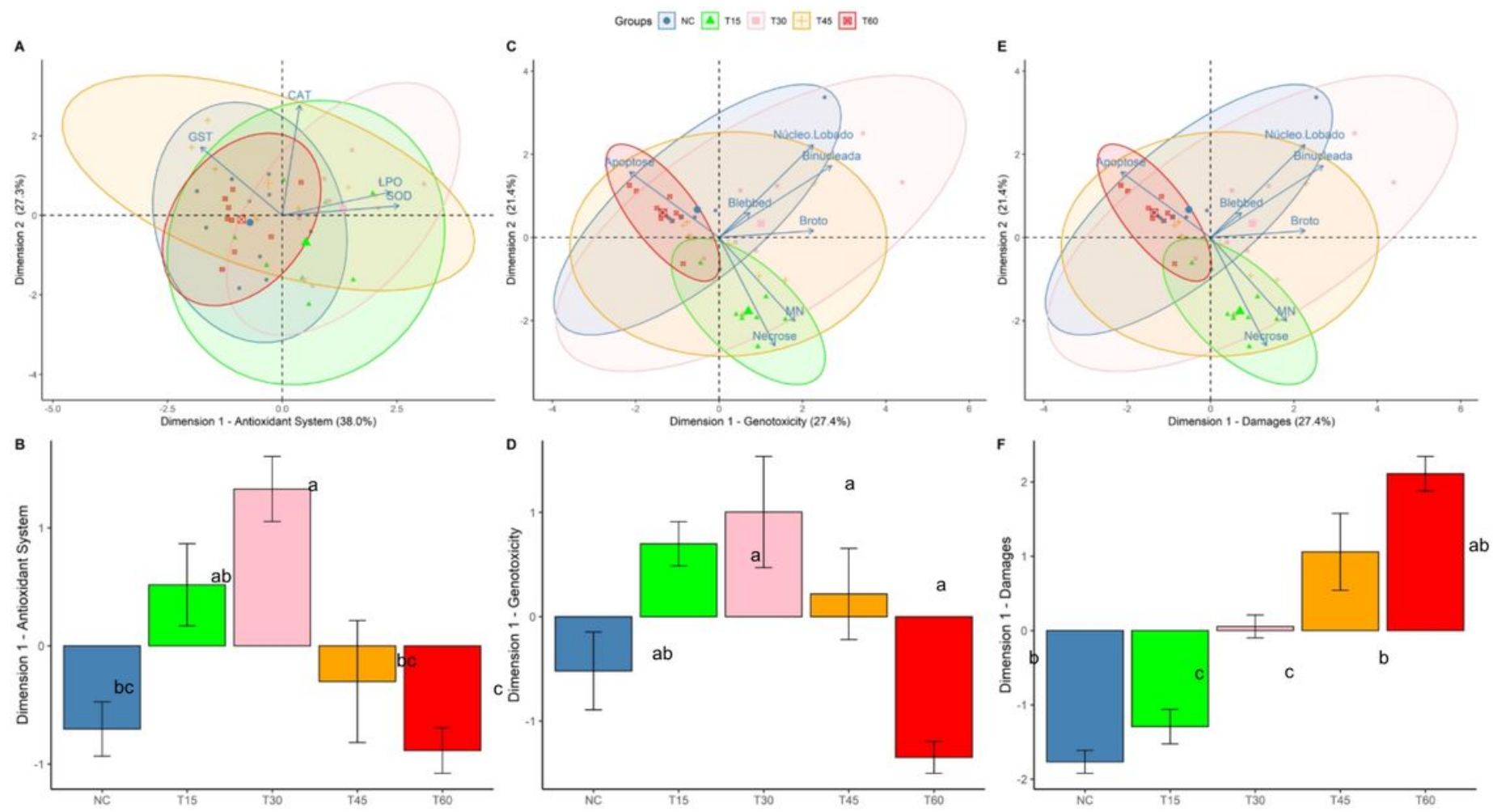

Figure 2

Ordering diagram of the principal component analysis and average \pm standard error barplot of the different systems analyzed in D. rerio exposed to $0.45 \mathrm{~g}_{\mathrm{L}} \mathrm{L}^{-1}$ of Metformin Hydrochloride at different times: Negative Control (NC - blue); 15 days (T15 - green); 30 days (T30 - pink); 45 days (T45 - orange); 60 days (T60 - red). A and B) Antioxidant System; C and D) DNA Demage; E and F) Tissue damages.
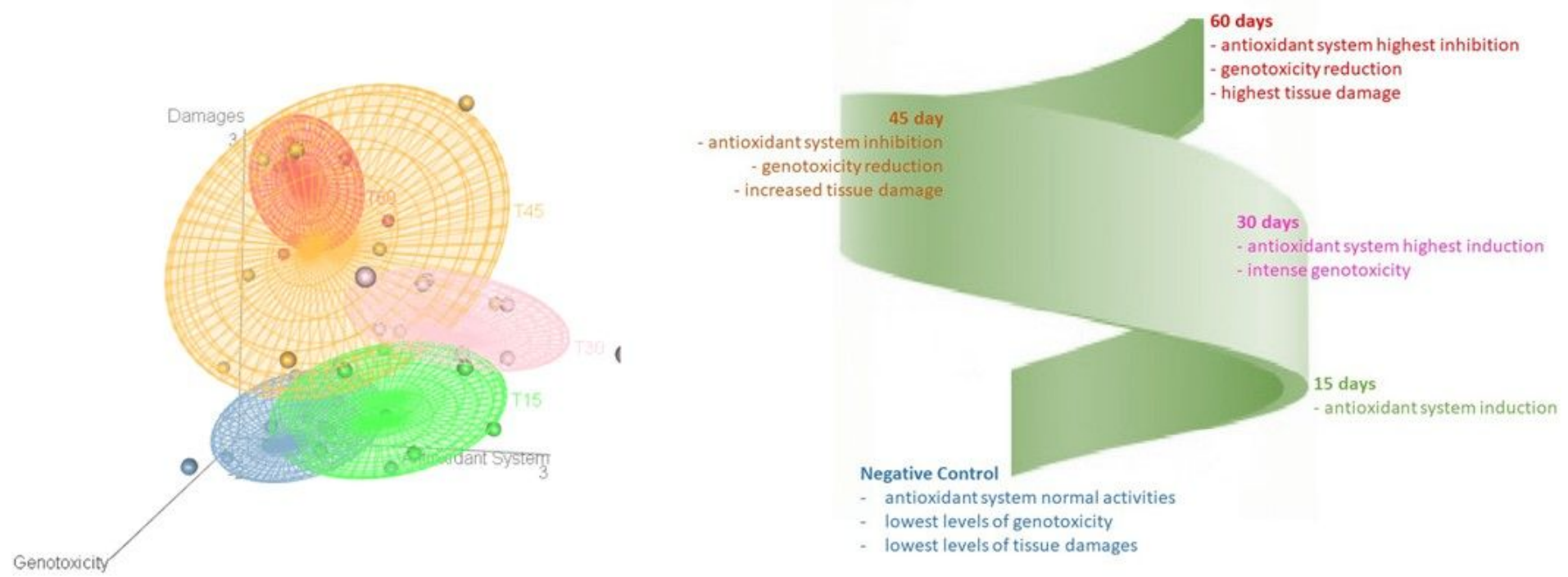

Figure 3 
Scheme of antioxidant system behavior and mutagenic potential in metformin hydrochloride chronic exposition. 